\title{
Development and validation of novel analytical methods for estimation of doxofylline in bulk and dosage forms
}

\author{
Atkuru Veera Venkata Naga Krishna Sunil Kumara,, Settaluri Vijaya Saradhib, \\ Chandra Bala Sekaranc and Tamanampudi Varahala Reddyd \\ a Department of Chemistry, NRI College, Vijayawada, 520 010, India \\ b Department of Biotechnology, Koneru Lakshmaiah University, Guntur district, 522 502, India \\ c Department of Biotechnology, Jagarlamudi Kuppuswamy Choudary College, Guntur, 522 006, India \\ d Department of Chemistry, Parvathaneni Brahmayya Siddhartha College of Arts and Sciences, Vijayawada, 520 010, India \\ *Corresponding author at: Department of Chemistry, NRI College, Vijayawada, 520 010, India. Tel.: +91.984.8834447; fax: +91.863 .2351028 . \\ E-mail address: balumphil@rediffmail.com (A.V.V.N.K.S. Kumar).
}

\section{ARTICLE INFORMATION}

Received: 27 January 2011

Received in revised form: 17 February 2011

Accepted: 24 February 2011

Online: 30 September 2011

\section{KEYWORDS}

\section{Doxofylline}

Ion association complex

Charge transfer complex

Ternary complex

Spectrophotometric analysis

Doxofylline analysis

\begin{abstract}
Three simple, sensitive and accurate spectrophotometric methods (A, B and C) were developed to determine doxofylline in bulk and in its dosage forms. Method A is based on charge-transfer complex formation of the drug with $p$-chloranilic acid. Method B involves the formation of colored chloroform extractable ion-pair complex of the drug with bromophenol blue under acidic condition. Method $\mathrm{C}$ is based on ternary complex formation of the drug with molybdenum(V) thiocyanate binary complex. The colored products are quantitated spectrophotometrically at 540, 390 and $690 \mathrm{~nm}$ by methods A, B and C, respectively. The variables, which affected the reactions were carefully studied and optimized. The linear ranges for the proposed methods were $4-32 \mu \mathrm{g} / \mathrm{mL}$ (method A \& B) and 2-16 $\mu \mathrm{g} / \mathrm{mL}$ (method C). Analytical performance of the methods was statistically validated. The proposed methods were successfully applied to the analysis of doxofylline in its dosage forms and were found to be comparable with that of reference method.
\end{abstract}

\section{Introduction}

Doxofylline (DFL) [1-5], chemically known as 7-(1,3dioxolan-2-ylmethyl)-1,3-dimethylpurine-2,6-dione (Figure 1), is a novel bronchodilator xanthine derivative drug, used in the treatment of bronchial asthma, chronic obstructive pulmonary disease (COPD) and chronic bronchitis. Animal and human studies have shown similar efficacy to theophylline but with significantly less side effects [6]. DFL differs from theophylline for the presence of a dioxalane group in position 7. DFL acts as a phosphodiesterase inhibitor and have decreased affinities toward adenosine A1 and A2 receptors which may account for the better safety profile of the drug $[7,8]$. The safety profile shows a better tolerability on cardiovascular, digestive and the central nervous systems [9]. DFL was found to be particularly effective in both decreasing the daily asthma attack rate as well as the beta-2- agonist consumption.<smiles>CN1C(=O)c2c(ncn2CC2OCCO2)N(C)C1O</smiles>

Figure 1. Structure of doxofylline.
The determination of DFL in pharmaceutical preparations is very important for safety and quality assurance. Various types of analytical procedures have been proposed for the analysis of DFL in bulk, pharmaceutical formulations and biological fluids. These procedures include HPLC [10-13], Stability indicating RPHPLC chromatography [14], LC-MS/MS [15], stability indicating HPTLC [16]. The above mentioned techniques are sensitive but require sophisticated equipment, tedious sample preparation and laborious clean up procedure prior to analysis. Visible spectrophotometry is considered the most widely used technique, because of its inherent simplicity, low cost and wide availability in most quality control laboratories. Therefore, they are a frequent choice for pharmaceutical analyses. Kamila et al. [17] and Joshi et al. [10] have reported UV spectrophotometric method for the quantification of DFL in pharmaceutical formulations. The literature is still poor in visible spectrophotometric methods for the determination of DFL in dosage forms.

Charge-transfer complex results from a donor-acceptor mechanism of Lewis acid-base reaction between two or more different chemical constituents. The formation of charge-transfer complex can be rapidly assessed for its validity as a simple quantitative analytical method for many drug substances which can act as electron donors. $p$-Chloranilic acid ( $\pi$ acceptor) has been investigated spectrophotometrically and has been successfully utilized in the determination of a variety of electrondonating basic compounds [18-27].

Ternary complex refers to a complex containing three different molecules, bound together. The general formula of the ternary complex denoted here as L-S-D (ligand L is the 
investigated drug, the second ligand $\mathrm{S}$ is $\mathrm{SCN}^{-}$and $\mathrm{D}$ is $\mathrm{Mo}$ ) has been widely used in spectrophotometric analysis of some drugs like chloroquine and pyrimethamine [28], ampicillin, dicloxacillin, flucloxacillin and amoxicillin [29], trazodone, amineptine and amitriptyline hydrochloride [30], metoclopramide and oxybuprocaine [31], and some H1antihistaminics [32] in pharmaceutical preparations using $\mathrm{Mo}(\mathrm{V})$ thiocyanate reagent.

The ion-pair complex is a special form of molecular complex resulting from two oppositely charged ions extractable into organic solvents from aqueous phase at suitable $\mathrm{pH}$. The ion-pair extractive spectrophotometry has been applied to the estimation of numerous compounds; possessing basic moieties (secondary or tertiary amino group) by using an anionic dye as a reagent and organic solvent as an extractant. Bromophenol blue being an anionic dye has been reported to form ion-pair complexes thus offering simple and rapid spectrophotometric determination of therapeutically significant pharmaceutical compounds [33-43].

However, the reaction between DFL and $p$-Chloranilic acid, $\mathrm{Mo}(\mathrm{V})$ thiocyanate reagent \& bromophenol blue hasn't been investigated yet. This paper describes three visible spectrophotometric methods for the assay of DFL in pure and dosage forms. Method A is based on charge transfer complexation between the drug as $n$-electron donor and $p$-chloranilic acid as $\pi$ acceptor. Method B utilizes the formation of an ion-pair complex of the drug with bromophenol blue and subsequent extraction of the yellow color into chloroform. Method C is based on ternary complex formation of the drug with molybdenum(V)thiocyanate binary complex. The proposed methods are optimized and validated as per the International conference on Hormonisation guidelines [44].

\section{Experimental}

\subsection{Instrumentation}

An ELICO double beam model SL 159 digital spectrophotometer with 1-cm matched quartz cells was used for all absorbance measurements.

\subsection{Materials and reagents}

All chemicals used were of analytical reagent grade and all solutions were freshly prepared in doubly distilled water.

\subsubsection{Method A}

$0.2 \% p$-Chloranilic acid: Prepared by dissolving $200 \mathrm{mg}$ of $p$-chloranilic acid (Merck, Mumbai) in $50 \mathrm{~mL}$ propyl alcohol and make up to $100 \mathrm{~mL}$ with chloroform (Merck, Mumbai).

\subsubsection{Method B}

$0.2 \%$ Bromophenol blue: Prepared by dissolving $200 \mathrm{mg}$ of bromophenol blue (Sdfine-Chem limited, Mumbai) in $100 \mathrm{~mL}$ of distilled water. $0.5 \mathrm{~N} \mathrm{HCl}$ : $1.825 \mathrm{~mL}$ of $\mathrm{HCl}$ (Fisher Scientific, Mumbai) was added to $100 \mathrm{~mL}$ of distilled water to get $0.5 \mathrm{~N} \mathrm{HCl}$. Chloroform (Sdfine-Chem limited, Mumbai).

\subsubsection{Method C}

0.001M Ammonium molybdate: Prepared by dissolving $123.6 \mathrm{mg}$ of ammonium molybdate (Sdfine-Chem limited, Mumbai) in $50 \mathrm{~mL}$ of distilled water in a $100 \mathrm{~mL}$ volumetric flask, then the volume was diluted up to the mark with distilled water. $10 \%$ Ammonium thiocyanate: Prepared by dissolving 10 $\mathrm{g}$ of ammonium thiocyanate (Sdfine-Chem limited, Mumbai) in $100 \mathrm{~mL}$ of distilled water. 10\% Ascorbic acid: Prepared by dissolving $10 \mathrm{~g}$ of ascorbic acid (Sdfine-Chem limited, Mumbai) in $100 \mathrm{~mL}$ of distilled water. 5\% Sodium lauryl sulphate: Prepared by dissolving $5 \mathrm{~g}$ of sodium lauryl sulphate (SdfineChem limited, Mumbai) in $100 \mathrm{~mL}$ of distilled water. $3 \mathrm{M}$ Hydrochloric acid: $10.95 \mathrm{~mL}$ of $\mathrm{HCl}$ (Fisher Scientific, Mumbai) was added to $100 \mathrm{~mL}$ of distilled water to get $3 \mathrm{M} \mathrm{HCl}$.

\subsection{Doxofylline tablet dosage forms}

The following dosage forms containing DFL was procured from the local pharmacy stores: Doxobid (400 mg, Reddy's Lab, Hyderabad), Synasma (400 mg, Ranbaxy, Mumbai), Doxfree (400 mg, Maceleods pharmaceuticals, Mumbai).

\subsection{Preparation of stock and working standard drug solutions}

Pharmaceutical grade DFL was kindly gifted by local pharmaceutical industry. A stock standard solution containing $1 \mathrm{mg} / \mathrm{mL}$ of DFL was prepared in chloroform (method A) and water (methods B \& C). Working standard solution equivalent to $200 \mu \mathrm{g} / \mathrm{mL}$ (methods A \& B) and $100 \mu \mathrm{g} / \mathrm{mL}$ (method C) of DFL was obtained by appropriate dilution of stock solution by chloroform (method A) and water (method B \& C).

\subsection{General assay procedure}

\subsubsection{Method A}

Into a series of $10 \mathrm{~mL}$ volumetric flasks, volumes (0.2-1.6 $\mathrm{mL})$ of DFL standard solution $(200 \mu \mathrm{g} / \mathrm{mL})$ equivalent to $4-32 \mu \mathrm{g}$ of the drug were transferred. To each flask, $1.5 \mathrm{~mL}$ of $0.2 \%$ $p$-chloranilic acid was added and brought up to the volume with chloroform. The absorbance of the pink colored product formed at room temperature $\left(25 \pm 1^{\circ} \mathrm{C}\right)$ was measured after $20 \mathrm{~min}$ of mixing at $540 \mathrm{~nm}$ against the reagent blank prepared similarly omitting the drug. The standard calibration curve was prepared to calculate the amount of the analyte drug in unknown samples.

\subsubsection{Method B}

Into a series of $100 \mathrm{~mL}$ separating funnels, volumes (0.2-1.6 $\mathrm{mL})$ of DFL standard solution $(200 \mu \mathrm{g} / \mathrm{mL})$ equivalent to $4-32 \mu \mathrm{g}$ of the drug, $0.5 \mathrm{~mL}$ of $0.5 \mathrm{~N} \mathrm{HCl}$ and $1.5 \mathrm{~mL} 0.2 \%$ bromophenol blue were transferred and mixed well. The funnels were shaken vigorously with $2 \times 5 \mathrm{~mL}$ chloroform for $2 \mathrm{~min}$, and then allowed to stand for clear separation of the two phases. The separated organic phase was transferred to a $10 \mathrm{~mL}$ volumetric flask. Then the extract was made up to the mark with chloroform and mixed well. The absorbance of the organic phase was measured at 390 $\mathrm{nm}$ against a reagent blank prepared similarly omitting the drug. The standard calibration curve was prepared to calculate the amount of the analyte drug in unknown samples.

\subsubsection{Method C}

Into a series of $10 \mathrm{~mL}$ volumetric flasks, volumes $(0.2-1.6$ $\mathrm{mL})$ of DFL standard solution $(100 \mu \mathrm{g} / \mathrm{mL})$ equivalent to $2-16 \mu \mathrm{g}$ of the drug were transferred. $2.5 \mathrm{~mL}$ of $0.001 \mathrm{M}$ ammonium molybdate, $1 \mathrm{~mL} 3 \mathrm{M} \mathrm{HCl}, 1 \mathrm{~mL} 10 \%$ ascorbic acid solution and $2 \mathrm{~mL}$ of $10 \%$ ammonium thiocyanate were added in heating tubes. Left for 15 minutes until complete formation of Mo (V) SCN complex, $1.5 \mathrm{~mL}$ of 5\% sodium lauryl sulphate was added, the mixture was homogenized by shaking, immersed in a water bath at $50{ }^{\circ} \mathrm{C}$ for 20 minutes, then cooled to room temperature. The mixture was diluted to volume with distilled water and the absorbance was measured at $690 \mathrm{~nm}$ against a blank prepared similarly omitting the drug. The standard calibration curve was prepared to calculate the amount of the analyte drug in unknown samples. 


\subsubsection{Reference method}

Absorption maxima of DFL $(20 \mu \mathrm{g} / \mathrm{mL})$ in $0.1 \mathrm{~N} \mathrm{HCl}$ was determined by scanning the drug solution from $200-400 \mathrm{~nm}$ and was found to be at $274 \mathrm{~nm}$. Into a series of $10 \mathrm{~mL}$ volumetric flasks, volumes of DFL standard solution equivalent to 4-30 $\mu \mathrm{g} / \mathrm{mL}$ of the drug were transferred and diluted to the mark with $0.1 \mathrm{~N} \mathrm{HCl}$. The absorbance of the solution was measured at 274 $\mathrm{nm}$ against the blank prepared similarly omitting the drug. The standard calibration curve was prepared to calculate the amount of the analyte drug in unknown samples.

\subsection{Procedure for the analysis of DFL in tablet dosage forms}

Ten tablets were weighed accurately and ground into a fine powder. An amount of powder equivalent to $100 \mathrm{mg}$ of DFL was weighed into a $100 \mathrm{~mL}$ volumetric flask, $50 \mathrm{~mL}$ of the chloroform (method A) or water (method B \& C) or $0.1 \mathrm{~N} \mathrm{HCl}$ (reference method) was added and shaken thoroughly for about $10 \mathrm{~min}$, then the volume was diluted up to the mark with the same solvents, mixed well and filtered using a quantitative filter paper. The filtered solution was appropriately diluted with the respective solvents. Convenient aliquots were subjected to analysis by the procedures described under method A, B \& C and reference method.

\section{Results and discussion}

\subsection{Mechanism of the reaction}

\subsubsection{Method A}

The results obtained in method A were due to the charge transfer reaction between the DFL and $p$-chloranilic acid to yield a pink colored product having maximum absorption at a wavelength of $540 \mathrm{~nm}$ against the corresponding reagent blank. $p$-chloranilic acid is a $\pi$ electron acceptor as a result of the strong electron withdrawing halo- and cyano- groups conjugated with the $\pi$-system. The DFL has tertiary amino group, which act as nelectron donor. Therefore, the DFL react with electron acceptor to form charge transfer complex or radical anions. The charge transfer complexes are formed through the lone pair of electrons donated by the DFL as n-donor and the $p$-chloranilic as an electron acceptor in which a partial ionic bond was assumed to be formed. This interaction was particularly strong on using $p$-chloranilic so that it involves a complete transfer of electronic charge with the formation of a free radical anion. These radical anions formed were the predominant chromogens in the reaction. The dissociation of the donor-acceptor complex in those reactions was promoted by the high ionizing power of the solvent, chloroform. A general reaction mechanism is proposed in Scheme 1.

\subsubsection{Method B}

The results obtained in method B were based on extractive spectrophotometry. The DFL exhibits basic character essentially due to the presence of tertiary amino group. DFL involves an ion association complex formation with acidic dye bromophenol blue under acidic conditions, which is extractable with chloroform from the aqueous phase, resulting in the formation of a yellow color solution having maximum absorption at a wavelength of $390 \mathrm{~nm}$ against the corresponding reagent blank. A general reaction mechanism is proposed in Scheme 2.

\subsubsection{Method C}

The results obtained in method $\mathrm{C}$ were due to the formation of ternary complex between the tertiary amine group of DFL and molybdenum (V) thiocyanate binary complex through the protonated nitrogen atom of the DFL. The reduction probability of Mo (VI) may occur by ascorbic acid in acidic media and react with thiocyanate to form a red binary Mo (V) $\mathrm{SCN}^{-}$complex.

The sensitivity and stability of the molybdenum (V) thiocyanate ion-pair binary complex is enhanced by using ascorbic acid.<smiles>CN1C(=O)c2c(ncn2CC2OCCO2)N(C)C1O</smiles>

Doxofylline<smiles>O=C1C(O)=C(Cl)C(=O)C(O)=C1Cl</smiles>

p-Chloranilic acid $n-\pi$ Complexation<smiles>CN1c2ncn(CC3OCCO3)c2C(=O)N(C)N(C)C1O</smiles><smiles>[Te]C1CC1</smiles><smiles>CN1C(=O)c2c(ncn2CC2OCCO2)N(C)C1O</smiles>

Doxofylline<smiles>[O-]c1c(O)c(Cl)c(Cl)c(O)c1Cl</smiles>

Free radicle form (Colored species)
Scheme 1<smiles>Cn1c(=O)c2c(ncn2CC2OCCO2)n(C)c1=O</smiles>

Doxofylline<smiles>CCCOC1CN(CC2CCOC2)c2c(n(C)c(=O)n(C)c2=O)N1</smiles>
$0.1 \mathrm{~N} \mathrm{HCl}$<smiles>O=S1(=O)OC(c2cc(Br)c(O)c(Br)c2)(c2cc(Br)c(O)c(Br)c2)c2ccccc21</smiles>

Bromophenol blue<smiles>O=S(=O)([O-])c1ccccc1C(c1cc(Br)c(O)c(Br)c1)c1cc(Br)c(O)c(Br)c1</smiles>

Ion pair complex

Scheme 2 


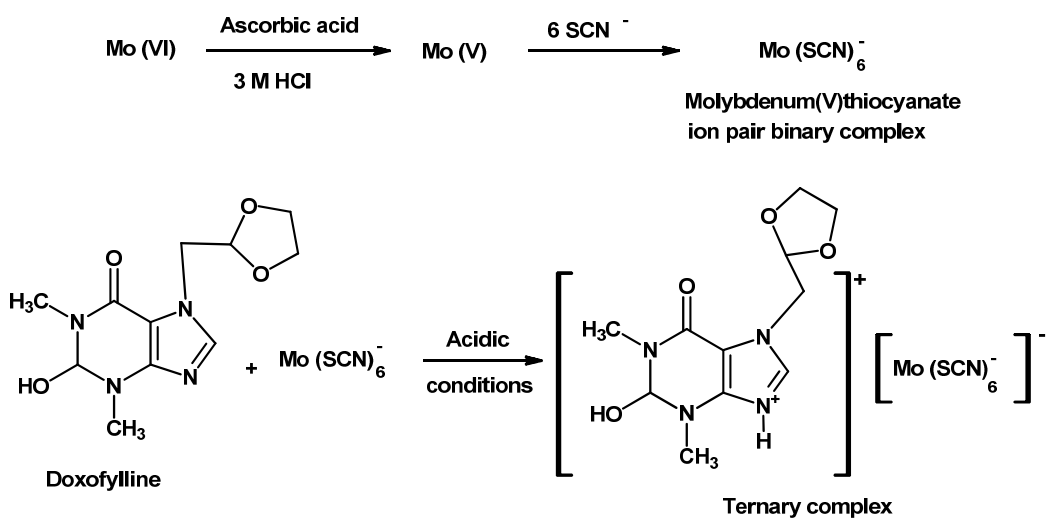

Scheme 3

The protonated form of DFL forms ternary complex with Mo (SCN)-6 resulting in the formation of a colored solution having maximum absorption at $690 \mathrm{~nm}$ against the corresponding reagent blank. Sodium lauryl sulphate increases the sensitivity of the color and avoids extraction of the complex. A general reaction mechanism is proposed in Scheme 3.

\subsection{Determination of optimum wavelength $\left(\lambda_{\max }\right)$ of the colored products}

The $\lambda_{\max }$ of the colored products produced in methods $\mathrm{A}, \mathrm{B}$ and $\mathrm{C}$ were determined by scanning them in the wavelength region of 380-760 $\mathrm{nm}$ against a corresponding reagent blank. Under the optimized experimental conditions each reagent blank showed negligible absorbance at the corresponding optimum wavelength. The $\lambda_{\max }$ of the colored products were found to be 540, 390 and $690 \mathrm{~nm}$ for methods A, B and C, respectively. The absorption spectrum of the proposed methods (A, B and C) is shown in Figure 2.

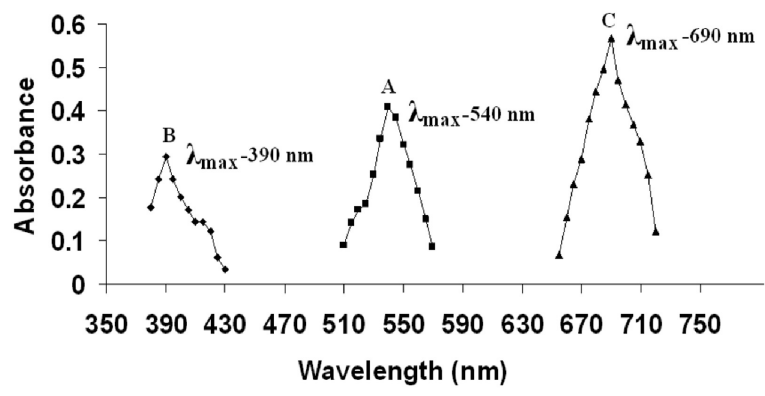

Figure 2. Absorption spectra of Doxofylline with (A). p-chloranilic acid, (B). Bromophenol blue and (C). Molybdenum (V) thiocyanate binary complex.

\subsection{Optimization of parameters}

The factors affecting reaction conditions (Concentration of $p$ Chloranilic acid, solvent used for dilution, reaction time and temperature in method A; Concentration of Bromophenol blue, acidity and solvent used for extraction in method $B$ Concentrations of Ammonium molybdate, Ammonium thiocyanate, Ascorbic acid, Sodium lauryl sulphate, acidity, reaction time and temperature in method C) were evaluated by altering each variable in turn while keeping the others constant and observing the effect produced on the absorbance of the colored species. The optimum values of the variables were maintained throughout the experiment to determine the concentration of DFL.

\subsubsection{Method A}

The color reaction was studied as a function of the concentration of $p$-chloranilic acid. The results indicated that the maximum color was obtained with $1.5 \mathrm{~mL}$ of $0.2 \% p$-chloranilic acid. The results obtained from optimization of the reaction time indicated that complete color development was attained after 20 min at room temperature. Different diluting solvents like methanol, ethanol, propanol, butanol, acetonitrile and chloroform were tested for appropriate dilution. The highest color intensity was attained when chloroform was used as the diluting solvent.

\subsubsection{Method B}

The optimization experiments have revealed that $1.5 \mathrm{~mL}$ of $0.2 \%$ bromophenol blue was sufficient for covering the broad range of Beer's law limit. Several organic solvents such as dichloromethane, chloroform, carbon tetrachloride and butanol were used for extracting the ion-association complex. Chloroform was selected because of its higher sensitivity and the considerably lower extraction of the dye. The effect of $\mathrm{pH}$ or acidity of the aqueous phase on the ion association complex was studied. The color intensity of the chloroform extract reached a maximum when $0.5 \mathrm{~mL}$ of $0.5 \mathrm{~N} \mathrm{HCl}$ was used.

\subsubsection{Method C}

The effect of volume of $0.001 \mathrm{M}$ ammonium molybdate and $10 \%$ ammonium thiocyanate on the absorbance of the colored product was studied. The maximum absorbance was obtained with $2.5 \mathrm{~mL}$ of ammonium molybdate and $2 \mathrm{~mL}$ of ammonium thiocyante. The optimum temperature and time required for the formation of ion pair binary (Mo (V) SCN) complex and ternary (Mo (V) SCN-drug) complex was 15 minutes at room temperature and 20 minutes at $50^{\circ} \mathrm{C}$ respectively. $1 \mathrm{~mL}$ of $3 \mathrm{M}$ $\mathrm{HCl}$ provides sufficient acidity for the formation of Mo (V) SCN complex. Sensitivity and stability of the molybdenum (v) thiocyanate ion-pair binary complex is enhanced by using $1 \mathrm{~mL}$ of $10 \%$ ascorbic acid. To avoid the extraction problem and to increase sensitivity of the method, many surfactants were examined; sodium lauryl sulphate, methylcellulose, benzalkonium chloride and tween 40 , the results obtained rivaled the maximum color observed in the presence of $1.5 \mathrm{~mL}$ of $5 \%$ sodium lauryl sulphate. 
Table 1. Quantitative parameters for the proposed methods.

\begin{tabular}{|c|c|c|c|}
\hline Parameters & Method A & Method B & Method C \\
\hline$\lambda_{\max }(\mathrm{nm})$ & 540 & 390 & 690 \\
\hline Beer's Limit $(\mu \mathrm{g} / \mathrm{mL})$ & 4-32 & $4-32$ & $2-16$ \\
\hline Molar Absorbtivity (L/mole/ cm) & $0.7822 \times 10^{4}$ & $0.8133 \times 10^{4}$ & $1.357 \times 10^{4}$ \\
\hline $\begin{array}{l}\text { Sandell's sensitivity } \\
\text { ( } \mu \mathrm{g} \mathrm{cm}^{-2} / 0.001 \text { Absorbance unit) }\end{array}$ & 0.0439 & 0.0714 & 0.0196 \\
\hline Stability of colored products (hours) & 3.0 & 2.5 & 4.0 \\
\hline \multicolumn{4}{|l|}{ Regression equation $(\mathrm{Y}=\mathrm{mx}+\mathrm{c})^{\mathrm{a}}$} \\
\hline Slope (m) & 0.0228 & 0.015 & 0.0502 \\
\hline Intercept (c) & -0.0035 & -0.0021 & -0.0023 \\
\hline Correlation coefficient (r) & 0.9993 & 0.9997 & 0.9996 \\
\hline $\mathrm{LOD}(\mu \mathrm{g} / \mathrm{mL})$ & 0.173 & 0.244 & 0.080 \\
\hline $\mathrm{LOQ}(\mu \mathrm{g} / \mathrm{mL})$ & 0.526 & 0.740 & 0.243 \\
\hline Standard deviation ${ }^{b}$ & 0.00120 & 0.00111 & 0.00122 \\
\hline Relative standard deviation (\%) & 1.318 & 0.916 & 1.38 \\
\hline \multicolumn{4}{|l|}{$\begin{array}{l}\text { \% Range of error } \\
\text { (Confidence Limits) }\end{array}$} \\
\hline 0.05 level & 1.10 & 0.766 & 1.15 \\
\hline 0.01 level & 1.630 & 1.1277 & 1.707 \\
\hline
\end{tabular}

a $Y=m x+c$, where $Y$ is the absorbance and $x$ is the concentration of drug in $\mu \mathrm{g} / \mathrm{mL}$.

${ }^{b}$ Average of six determinations.

Table 2. Recovery studies by standard addition method.

\begin{tabular}{|c|c|c|c|c|c|c|}
\hline Method & Formulation & Labeled claim (mg) & Pure drug added (mg) & Found \pm S.D $(n=5)$ & Recovery (\%) & RSD \\
\hline \multirow{3}{*}{$\mathbf{A}$} & Doxobid & 400 & 10 & $409.06 \pm 0.543$ & 99.77 & 0.132 \\
\hline & Synasma & 400 & 10 & $411.06 \pm 0.696$ & 100.02 & 0.170 \\
\hline & Doxfree & 400 & 10 & $411.26 \pm 0.928$ & 100.30 & 0.227 \\
\hline \multirow{3}{*}{ B } & Doxobid & 400 & 10 & $408.67 \pm 0.854$ & 99.67 & 0.209 \\
\hline & Synasma & 400 & 10 & $412.45 \pm 0.649$ & 100.59 & 0.159 \\
\hline & Doxfree & 400 & 10 & $410.15 \pm 0.624$ & 100.03 & 0.153 \\
\hline \multirow{3}{*}{ C } & Doxobid & 400 & 10 & $410.79 \pm 0.612$ & 100.19 & 0.150 \\
\hline & Synasma & 400 & 10 & $409.68 \pm 0.593$ & 99.92 & 0.145 \\
\hline & Doxfree & 400 & 10 & $411.89 \pm 0.867$ & 100.46 & 0.212 \\
\hline
\end{tabular}

\subsection{Validation}

Validation was carried out by assessing the parameters like linearity range, precision, accuracy, detection and quantification limits according to the International Conference on Harmonisation (ICH) guidelines for validation of analytical procedures.

A linear correlation was found between absorbance at $\lambda_{\max }$ and concentration of DFL for all the three methods (A, B and C). The graphs showed negligible intercept and are described by the equation:

$\mathrm{Y}=a+b \mathrm{X}$

where $\mathrm{Y}=$ absorbance of 1 -cm layer of solution, $a=$ intercept, $b=$ slope, $\mathrm{X}=$ concentration of drug in $\mu \mathrm{g} / \mathrm{mL}$.

The linearity was evaluated by linear regression analysis of the Beer's law data by least-square regression method, which was used to calculate the correlation coefficient, intercept and slope of the regression line and the values are presented in Table 1. The optical characteristics such as Beer's law limits, molar absorptivity and Sandell's sensitivity values of the proposed methods were calculated and are summarized in Table 1.

In order to determine the intraday accuracy and precision of the proposed methods (A, B and C), solution containing fixed concentration (within the working limits) of the drug was prepared and analyzed in six replicates by the proposed methods under the optimized experimental conditions. The standard deviation, relative standard deviations and recoveries obtained in the intra day analyses by methods A, B and C were calculated and are summarized in Table 1 . The relative standard deviation indicates the high intra-day precision of the methods. Regarding the accuracy evaluation, good recoveries were obtained (Table 1). The percent recovery indicated good accuracy and an agreement between the theoretical value and the real value of concentration. Thus the proposed methods are effective for the determination of DFL.

Sensitivity of the proposed methods was evaluated by calculating Limit of detection (LOD) and limit of quantification
(LOQ). LOD is the lowest detectable concentration of the analyte by the method while $\mathrm{LOQ}$ is the minimum quantifiable concentration. LOD and LOQ were calculated by equations: LOD $=\delta 3.3 / \mathrm{s}$ and $\mathrm{LOQ}=\delta 10 / \mathrm{s}$, respectively, where $\delta$ is the standard deviation of blank and $s$ is slope of calibration. The results (Table 1) indicating proposed methods are highly sensitive.

The reliability and accuracy of the proposed methods were further confirmed by performing recovery studies by standard addition method. To a fixed and known quantity of the preanalyzed tablet, pure drug $(10 \mathrm{mg})$ was added and the total was found by the proposed methods (A, B and C). The results of recovery study are complied in Table 2 . The percent recoveries of the pure drug added was quantitative and additionally reveal the fair selectivity of the method.

\subsection{Application of the proposed methods for the analysis of tablets}

The proposed methods (A, B and C) were successfully applied to the determination of DFL in three different brands of tablet dosage forms. The results are summarized in Table 3. The results obtained were statistically compared with the reference method [10] by applying the Student's t-test and F-test for accuracy, precision respectively. The calculated t-value and Fvalue at $95 \%$ confidence level did not exceed the tabulated values of 2.77 and 6.39, respectively, for eight degrees of freedom. The tests indicate that there is no difference between the proposed methods and the reference method with respect to accuracy and precision.

\section{Conclusion}

The methods reported for the estimation of DFL has the advantages of simplicity, sensitivity, accuracy and is associated with higher sensitivity and precision. The developed spectrophotometric methods are cheaper than the reported liquid chromatographic methods for analysis of DFL in the pharmaceutical preparations. 
Table 3. Determination of doxofylline in pharmaceutical formulations using the proposed and reference methods.

\begin{tabular}{|c|c|c|c|c|c|c|}
\hline Method & Formulation & Labeled claim (mg) & Found \pm S.D $(n=5)$ & Recovery (\%) & $F^{*}$ value & $\mathbf{t}^{*}$ value \\
\hline \multirow{3}{*}{ Reference } & Doxobid & 400 & $399.80 \pm 0.569$ & 99.95 & --- & --- \\
\hline & Synasma & 400 & $405.80 \pm 0.324$ & 101.45 & --- & --- \\
\hline & Doxfree & 400 & $400.24 \pm 0.445$ & 100.06 & --- & --- \\
\hline \multirow{3}{*}{ A } & Doxobid & 400 & $398.75 \pm 0.648$ & 99.68 & 1.87 & 0.34 \\
\hline & Synasma & 400 & $400.06 \pm 0.491$ & 100.01 & 1.46 & 0.67 \\
\hline & Doxfree & 400 & $405.05 \pm 0.594$ & 101.26 & 2.11 & 0.58 \\
\hline \multirow{3}{*}{ B } & Doxobid & 400 & $396.45 \pm 0.496$ & 99.11 & 2.69 & 0.82 \\
\hline & Synasma & 400 & $406.25 \pm 0.378$ & 101.56 & 1.27 & 0.39 \\
\hline & Doxfree & 400 & $389.45 \pm 0.516$ & 97.36 & 1.84 & 0.67 \\
\hline \multirow{3}{*}{ C } & Doxobid & 400 & $399.84 \pm 0.660$ & 99.96 & 2.45 & 0.76 \\
\hline & Synasma & 400 & $402.16 \pm 0.473$ & 100.54 & 1.59 & 0.43 \\
\hline & Doxfree & 400 & $397.56 \pm 0.333$ & 99.39 & 1.39 & 0.61 \\
\hline
\end{tabular}

${ }^{*}$ Tabulated $t$ value at $95 \%$ confidence level $=2.77$ and Tabulated $\mathrm{F}$ value at $95 \%$ confidence level $=6.39$.

The non-interference of tablet excipients makes the methods suitable for the estimation of the drug in tablets and hence can be used for routine quality control of DFL formulations.

\section{Acknowledgement}

The authors express their gratitude to the management Parvathaneni Brahmayya Siddhartha College of Arts and Sciences, Vijayawada, Andhra Pradesh for providing research facilities.

\section{References}

[1]. Cirillo, R.; Barone, D.; Franzone, J. S. Arch. Int. Pharmacodyn. Ther. 1988 295, 221-237.

[2]. Poggi, R.; Brandolese, R.; Bernasconi, M.; Manzin, E.; Rossi, A. Chest 1989, 96, 772-780.

[3]. Dini, F. L.; Cogo, R. Curr. Med. Res. Opin. 2001, 16, 258-268.

[4]. Sankar, J.; Lodha, R.; Kabra, S. K. Indian J. Pediatr. 2008, 75, 251-255.

[5]. Dali, S.; Subhashis, C.; Sanjay, S.; Brahmeshwar, M. Expert Opin Pharmaco. 2009, 10, 2343-2356.

[6]. Goldstein, M. F.; Chervinsky, P. Med. Sci. Monit. 2002, 8, CR297-304

[7]. Dini, F. L.; Frank, L. D.; Roberto, C. Curr. Med. Res. Opinion. 2000, 16 258-268.

[8]. Melillo, G.; Balzano, G.; Jodice, F.; De, F. A.; Campisi, V.; Capone, M.; Di, F. A.; Foddai, G.; Franzone, J. S.; Grossi, E. Int. J. Clin. Pharm. Res. 1989, 9, 397-405.

[9]. Franzone, J. S.; Cirillo, R.; Biffignandi, P. Eur. J. Pharmacol. 1989, 165, 269-277.

[10]. Joshi, H. R.; Patel, A. H.; Captain, A. D. J. Young Pharm. 2010, 2, 289-296.

[11]. Tagliaro, F.; Dorizzi, R.; Frigerio, A.; Marigo, M. Clin. Chem. 1990, 36 113-118.

[12]. Lagana, M. B.; Marino, A.; Mancini, M. Biomed. Chromatogr. 1990, 4 205-207.

[13]. Ashu, M.; Shikha, P. J. Anal. Chem. 2010, 65, 293-297.

[14]. Gannu, R.; Bandari, S.; Sudke, S. G.; Rao, Y. M.; Shankar, B. P. Acta Chromat. 2007, 19, 149-160.

[15]. Sreenivas, N.; Narasu, M. L.; Shankar, B. P.; Mullangi, R. Biomed. Chromatogr. 2008, 22, 654-661.

[16]. Narendra, G. P.; Sathiyanarayanan, L.; Mahadeo, V. M.; Sunil, R. D. J Planar Chromatogr. -Mod. TLC. 2009, 22, 345-348.

[17]. Kamila, M. M.; Mondal, N.; Ghosh, L. K. Indian J. Chem. Tech. 2007, 14, 523-525.

[18]. Rahman, N.; Manirul, H. Anal. Chem. Insights. 2008, 3, 31-43.

[19]. El-Brashy, A. M; El-Sayed, M. M.; El-Sepai, F. A. Bull. Korean Chem. Soc. 2004, $25,365-372$.

[20]. Chukwurah, B. K.; Ajali, U. Boll. Chim. Farm. 2001, 140, 354-360.

[21]. Okide, G. B.; Odoh, U. E.; Ajali, U. Boll. Chim. Farm. 2002, 141, 299-303.

[22]. Refat, M. S.; El-Didamony, A. M. Spectrochim. Acta A: Mol. Biomol. Spectrosc. 2006, 65, 732-741.

[23]. Prameela Rani, A.; Sekaran, C.; Archana, N.; Teja, P. S.; Aruna, B. Int. J. Chem. Sci. 2009, 7, 1642-1652.

[24]. El Ragehy, N. A.; Badawy, A. M.; El Khateeb, S. Z. Analyt. Lett. 1995, 28, 2363-2378.

[25]. Siddiqui, M. R.; Tariq, A.; Ahmad, A.; Chaudhary, M.; Shrivastava, S. M.; Singh, R. K. Asian J. Sci. Res. 2009, 2, 135-145.

[26]. Mahrous, M. S.; Abdel Salam, M.; Issa, A. S.; Abdel-Hamid, M. Talanto 1986, 33, 185-186.

[27]. Okide, G. B.; Odoh, U. E. Indian J. Pharm. Sci. 1998, 60(6), 368-370.

[28]. Khalil, S. M.; Mohamed, G. G.; Zayed, M. A.; Elqudaby, H. M. J. Microchem 2000, 64, 181-186.
[29]. Mohamed, G. G. J. Pharm. Biomed. Anal. 2001, 24, 561-567.

[30]. Mohamed, G. G. ; Nour El-Dien, F. A.; Khalil, S. M.; Nehad, A. M. Spec. Acto A: Mol. Biomol. Spec. 2006, 65, 1221-1226.

[31]. Abdel-Gawad, F. M.; El-Ginudi, N. M. Anal. Lett. 1995, 28, 1437-1447.

[32]. Hassan, W. S.; El-Henawee, M. M.; Gouda, A. A. Spectrochim. Acta A Mol. Biomol. Spectrosc. 2008, 69, 245-255.

[33]. Rahman, N.; Hejaz-Azmi, S. N. J. Pharm. Biomed. Anal. 2000, 24, 33-41.

[34]. Rahman, N.; Ahmad, K. N.; Hejaz, A. S. N. Farmaco. 2004, 59, 47-54.

[35]. El-Didamony, A. M. Arch. Pharm. (Weinheim) 2005, 338, 190-197.

[36]. Ashour, S.; Al-Khalil, R. Il Farmaco. 2005, 60, 771-776.

[37]. Onal, A.; Kepekçi, S. E.; Oztunc, A. J. AOAC Int. 2005, 88, 490-495.

[38]. Basavaiah, K.; Charan, V. S. Indian Pharmacist. 2003, 2, 96-100.

[39]. El-Kerdawy, M. M.; Moustafa, M. A.; El-Ashry, S. M.; El-Wazzi, D. R. Anal. Lett. 1993, 26, 1669-1680.

[40]. Sodhi, R. A.; Chawla, J. L.; Sane, R. T. Indian Drugs 1997, 34, 512-521.

[41]. Rajput, S. J.; Vyas, A. G. Indian Drugs 1998, 35, 352-357.

[42]. Somashekara.; Ramappa, P. G.; Revanasiddappa, H. D. Indian Drugs 2001, 38, 97-99.

[43]. Basavaiah, K.; Charan, V. S. Science Asia. 2004, 30, 163-170.

[44]. Validation of Analytical Procedures; Methodology, International Conference on Harmonization (ICH): Text and Methodology Q2 (R1): Complementary Guideline on Methodology dated 06 November 1996: incorporated in November 2005, London. 